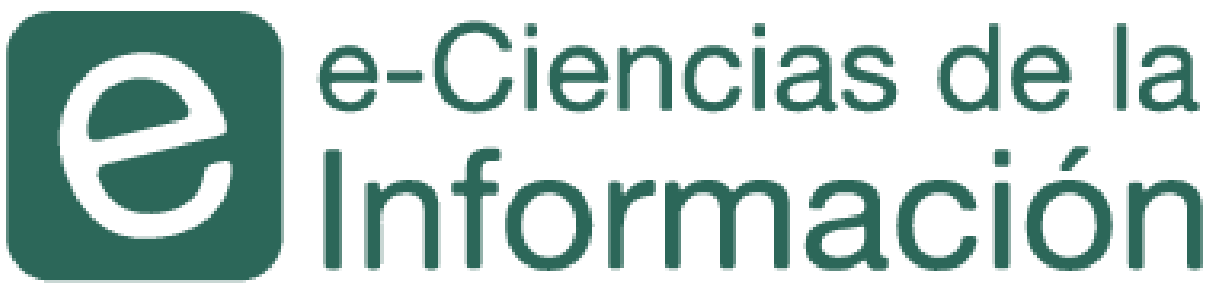

Evaluación del Sistema de Bibliotecas de la Organización para Estudios Tropicales (OET)

Susana Aguilar Zumbado $>$ Magda Cecilia Sandí Sandí $>$ Rebecca Vargas Bolaños Publicado 01 de julio, 2015 / Artículo Científico 2

Revista electrónica semestral ISSN 1659-4142

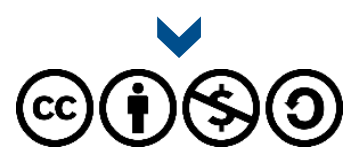

Universidad de Costa Rica

Visite el sitio web de e-Ciencias de la Información 


\title{
$>$ Evaluación del Sistema de Bibliotecas de la Organización para Estudios Tropicales (OET) 1
}

\author{
Evaluation Library System of the Organization for Tropical Studies (OTS) \\ Susana Aguilar Zumbado ${ }^{2}$ \\ > Magda Cecilia Sandí Sandi ${ }^{3}$ \\ $>$ Rebecca Vargas Bolaños ${ }^{4}$
}

\section{RESUMEN}

En este artículo se muestran los principales resultados del Trabajo Final de Graduación titulado "Diagnóstico del Sistema de Bibliotecas de la Organización para Estudios Tropicales (OET), periodo 2013: Propuesta para el mejoramiento de sus servicios y productos de información", el cual formó parte esencial del proyecto de investigación " Propuesta de diseño de servicios y productos virtuales especializados en el campo de la biodiversidad ", inscrito en la Escuela de Bibliotecología y Ciencias de la Información de la Universidad de Costa Rica. Esta investigación es de tipo cuantitativo y se define como descriptiva. Se realizó un diagnóstico para conocer el perfil de las personas usuarias del sistema de bibliotecas de la OET, así como sus necesidades de información, por medio de seis cuestionarios dirigidos a diferentes poblaciones usuarias del sistema. El periodo de estudio fue de marzo a julio del 2013. Entre los principales resultados se aprecia que el Sistema de Bibliotecas es de gran importancia para la comunidad científica al que está dirigido; sin embargo, sus servicios y productos requieren de una mayor proyección en el área para poder aprovechar la riqueza documental que alberga en sus cuatro bibliotecas.

\section{ABSTRACT}

This article shows the main findings about the thesis entitled "Proposal for the improvement of its services and information products Library System Diagnosis of the Organization for Tropical Studies (OTS), 2013 period: Proposed design virtual products and services specialized in the field of biodiversity". This research was register in the School of Library and Information Sciences at the University of Costa Rica. This study was a quantitative focus and defined as descriptive. Was necessary made a diagnosis about to know the profile of the users of the library system OTS and their information needs, through six different questionnaires at their user population. The study period was from March to July 2013. The main result shows that the libraries are of great importance for the scientific community to which it is addressed; however, their services and products require greater projection in the area to take advantage of the collections in the four libraries.

\section{Palabras clave}

\section{Bibliotecas, necesidades de información, biodiversidad, Organización para Estudios Tropicales, Universidad de Costa Rica, Costa Rica}

\section{Keywords}

Libraries, information needs, biodiversity, Organization for Tropical Studies, University of Costa Rica, Costa Rica

1 Este artículo es producto del primer proyecto desarrollado conjuntamente entre la Escuela de Bibliotecología y Ciencias de la Información (EBCl) de la Universidad de Costa Rica (UCR) y la Organización para Estudios Tropicales (OET), titulado Propuesta de diseño de servicios y productos virtuales especializados en el campo de la biodiversidad. El proyecto fue realizado en el marco del convenio de cooperación firmado entre ambas instituciones en el año 2012.

2 Organization for Tropical Studies (OTS). COSTA RICA. saguilarz@gmail.com

3 Universidad de Costa Rica. Escuela de Bibliotecología y Ciencias de la Información. COSTA RICA. magda.sandi@ucr.ac.cr

4 Universidad de Costa Rica. Escuela de Bibliotecología y Ciencias de la Información. Instituto de Investigación en Educación. COSTA RICA. rebeca.vargas@ucr.ac.cr 


\section{1.}

\section{Introducción}

Debido a la importancia de la temática del Sistema de Bibliotecas de la OET y a la necesidad de proyectar sus servicios y productos, la $\mathrm{EBCl}$ se convierte en el ente más interesado en mejorar su quehacer y poner a disposición del público interesado una unidad de información especializada de vanguardia, este es el objetivo principal del convenio de cooperación. Durante el desarrollo de la investigación se involucró a una estudiante de grado para realizar su Trabajo Final de Graduación, con el fin de que apoyara el desarrollo del diagnóstico planteado en los objetivos del proyecto Diagnóstico del Sistema de Bibliotecas de la Organización para Estudios Tropicales (OET), periodo 2013: Propuesta para el mejoramiento de sus servicios y productos de información, el cual fue elaborado por la señorita Susana Aguilar Zumbado y defendido en el año 2014.

En Costa Rica existen diferentes organismos que trabajan en beneficio de los recursos naturales y que ayudan a controlar y disminuir el daño irreparable causado por el ser humano, uno de ellos es la Organización para Estudios Tropicales, institución preocupada desde su fundación por el cuidado, la preservación, la educación y la investigación de la naturaleza. Sus inicios se remontan a principios de la década de 1960. Actualmente agrupa a setenta instituciones de investigación de los Estados Unidos, América Latina y Australia. Entre las actividades que ha desarrollado para cumplir con su misión se tiene el establecimiento de tres estaciones biológicas: Estación Biológica La Selva, ubicada en Sarapiquí; Estación Biológica Las Cruces, en San Vito de Coto Brus; y la Estación Biológica Palo Verde, en el Parque Nacional Palo Verde en Bagaces. Tanto sus oficinas centrales ubicadas en la Ciudad de la Investigación en la Universidad de Costa Rica como sus estaciones biológicas cuentan con una biblioteca cada una. Estas cuatro bibliotecas forman el Sistema de Bibliotecas de la Organización para Estudios Tropicales, especializadas en biología tropical. Preservan los documentos que genera la institución, además de rescatar, organizar y diseminar la información sobre esta temática.

En este sistema, anualmente se atienden diversos tipos de personas usuarias, tales como estudiantado universitario, investigadores e investigadoras, estudiantes de los cursos que imparte la OET, profesorado universitario, personal de la OET y usuarios virtuales de diferentes países. En las bibliotecas de las estaciones biológicas no se lleva un control estadístico de la cantidad de consultas, solamente se realiza en la biblioteca central. En el 2011 se atendieron un promedio de 300 consultas; y durante el 2012, hasta el mes de setiembre, se registraron 347 solicitudes de información. Por falta de tecnología, estos datos no contabilizan el uso que se le puede estar dando a las bases de datos a través de Internet, donde más de 15 mil artículos se ofrecen digitalmente.

Este sistema de bibliotecas cuenta con más de 7 mil libros, 11 mil separatas, 500 tesis, 1000 documentos monográficos, 15 mil artículos en texto completo, 50 títulos de publicaciones periódicas y con cuatro bases de datos especializadas que suman en total más de 53 mil registros bibliográficos. Sin duda, los niveles de producción de información científica han ido en 
aumento. Este índice de crecimiento es muy elevado, situación que podría considerarse normal reflexionando sobre lo afirmado por Rubio Liniers (1999, p. 144):

Price formuló una ley según la cual el crecimiento de la ciencia es exponencial, siendo su ritmo más rápido que la mayoría de los fenómenos sociales. Mientras que la población se duplica cada 50 años, la literatura científica se convierte en el doble en 10 años.

Se deben tomar las medidas necesarias para gestionar y evaluar este crecimiento. Si no se cuenta con los métodos adecuados para su organización, orden, interpretación, almacenamiento, análisis y evaluación, posiblemente toda esta literatura permanezca estática y no como una producción literaria importante que en su conjunto proyecte datos sobre el comportamiento de la ciencia.

Las bibliotecas tienen como uno de sus principales objetivos la transmisión y difusión de la información. Conforme avanza el desarrollo científico y tecnológico, el significado de ellas se ha ido transformando. La explosión de la información, la Internet, el uso de las redes sociales, la difusión de información, la aparición del documento digital, el crecimiento exponencial del conocimiento, las tendencias de la $W e b$, el software libre, el surgimiento de las bibliotecas digitales, virtuales, híbridas, electrónicas, la globalización, entre otros, son algunos de los factores que han llevado a las bibliotecas a enfrentarse al gran reto de ir evolucionando conforme avanza la sociedad de la información. Sobre este tema Stueart y Moran comentan:

Las bibliotecas son hoy en día organizaciones excitantes, innovadoras, cambiantes y aún turbulentas. El cambio requiere la interacción humana y tecnológica para su éxito. La aceleración del cambio - en la tecnología, movilidad, urbanización, internacionalización, economía- ha afectado a las bibliotecas tanto como a cualquier otra organización. (1998, p. 323)

Sin embargo, algunas bibliotecas no han podido enfrentar adecuadamente estos retos y cambios, por lo que se han visto amenazadas, rezagadas y obsoletas, y han llegado incluso a desaparecer. Probablemente, algunas causas por las cuales las bibliotecas no se han desarrollado paralelamente al avance de la ciencia y la tecnología son:

a. El personal gerente y administrativo de las instituciones a las cuales pertenecen desconocen la importancia de las bibliotecas en la sociedad..

b. Estas bibliotecas no han tenido un crecimiento de acuerdo con las necesidades de su comunidad.

c. Las bibliotecas, al no aportar a corto plazo a la economía del entorno en el que se encuentran, se les resta importancia.

d. Se da una limitada gestión de la información dentro de las bibliotecas.

e. Hay un escaso presupuesto asignado para cubrir los servicios que ofrecen.

f. Cuentan con colecciones bibliográficas y digitales con información obsoleta.

g. El perfil profesional del recurso humano que trabaja en estas unidades no responde a los objetivos de la biblioteca moderna. 
h. No cuentan con el recurso humano adecuado para cubrir la totalidad de sus necesidades.

Ante este panorama, la situación en las bibliotecas se puede tornar aún más compleja, ya que no solamente se trata de ofrecer tecnología novedosa, colecciones actuales, servicios y productos de calidad, sino que cualquier actividad o tarea que se realice en las unidades de información deben ir orientada a su razón de ser: las personas usuarias. Lau advierte que la satisfacción de estas debe ser "la aspiración y tarea diaria de las bibliotecas; una misión vital que debe tenerse en mente a la hora de operar los procesos administrativos de organización y oferta de servicios" (2011, p. 11).

Por lo tanto, un factor determinante en las bibliotecas no es solamente buscar la excelencia y la calidad de sus servicios y productos de información, sino asegurar la eficacia dirigida a la satisfacción de sus clientes. Como bien lo comenta Calva González:

La satisfacción de los usuarios es uno de los fines que tienen las bibliotecas o cualquier otra unidad de información. A ella se dirigen todos los esfuerzos del personal, el desarrollo de las colecciones y los servicios que se brindan. Pueden existir colecciones planeadas y recursos económicos para su mantenimiento constante, pero el usuario puede no estar satisfecho sino obtuvo la información que necesitaba en ese momento. Asimismo, la biblioteca puede tener excelentes servicios bien estructurados como lo indican los cánones bibliotecológicos para una biblioteca y resultar que el usuario, que los utiliza, no está satisfecho porque no le dieron la información que necesitaba. (2011, p. 15)

En consecuencia, ¿cómo evitar el rezago y la obsolescencia en las bibliotecas?, ¿cómo lograr la satisfacción de las personas usuarias y a la vez ofrecer servicios de calidad? y ¿cómo medir el avance y excelencia de las tareas, las prácticas y los procedimientos en las unidades de información? Los diagnósticos y las evaluaciones son una respuesta a estas interrogantes, por lo que Ruiz Vaca y Martínez Arellano afirman:

Durante mucho tiempo las bibliotecas operaron sin llevar a cabo un proceso de evaluación: se daba por hecho que si en éstas no existía ningún tipo de queja, toda la biblioteca funcionaba satisfactoriamente. Sin embargo, con el paso del tiempo la evaluación se fue convirtiendo en un elemento esencial para la buena gestión de cualquier biblioteca. De esta forma, la evaluación se convirtió en una herramienta de primer orden para mejorar las actividades y los servicios de la biblioteca. (2011, p. 67)

De acuerdo a la importancia de la información científica que maneja la OET, la cantidad de documentos en diversos formatos que posee y la variedad de personas usuarias que atiende, el problema de la investigación es la ausencia de un diagnóstico en el Sistema de Bibliotecas de la Organización para Estudios Tropicales que permita identificar ¿quiénes son su clientela?, ¿qué hacen?, ¿para qué solicitan información?, ¿cuáles son sus necesidades de información?, ¿cuáles son sus colecciones bibliográficas y digitales?, ¿cuál es su recurso humano, físico y tecnológico?, ¿cuál es su presupuesto?; y también conocer ¿cuáles son sus prácticas, sus procesos administrativos, los servicios y los productos de información? 
Los diagnósticos en las unidades de información permiten cumplir objetivos institucionales, alcanzar metas y efectividad en las labores que se llevan a cabo en las bibliotecas, es decir, posibilitan promover una adecuada gestión de la información, recomendada por ejemplo en el convenio sobre la Diversidad Biológica abierto a su firma desde el 5 de junio de 1992 hasta el 4 de junio de 1993 en la conferencia de las Naciones Unidas sobre el Medio Ambiente y el Desarrollo ("Cumbre de la Tierra" de Río de Janeiro), período en el cual firmaron 168 países. Costa Rica lo firmó y ratificó el 13 de junio de 1992. El Artículo 17 de este convenio, sobre el intercambio de información define lo siguiente:

1. Las Partes Contratantes facilitarán el intercambio de información de todas las fuentes públicamente disponibles pertinente para la conservación y la utilización sostenible de la diversidad biológica, teniendo en cuenta las necesidades especiales de los países en desarrollo.

2. Ese intercambio de información incluirá el intercambio de los resultados de las investigaciones técnicas, científicas y socioeconómicas, así como información sobre programas de capacitación y de estudio, conocimientos especializados, conocimientos autóctonos y tradicionales, por sí solos y en combinación con las tecnologías mencionadas en el párrafo 1 del artículo 16. También incluirá, cuando sea viable, la repatriación de la información. (Naciones Unidas, 1992, p. 12)

El Sistema de Bibliotecas de la OET, trabaja sobre esta línea, incluyendo dentro de sus principales tareas la recopilación y difusión de las investigaciones científicas que se han publicado sobre Costa Rica en el campo de la biología tropical y temas afines. Por ello desde 1996 desarrolla una base de datos llamada Bibliografía Nacional en Biología Tropical - Costa Rica (Binabitrop CR), que contiene estas investigaciones y posee 38500 registros. En muchos de los casos se ha tenido que repatriar la información. En Ugalde Gómez et al.(2009), sobre esta base de datos se dice que: "es quizá la más completa del país en cuanto a información sobre el trópico. De fácil manejo y búsquedas" (p. 163).

Es necesario realizar diagnósticos y evaluaciones que permitan medir las condiciones actuales de dichas bibliotecas. Estos llegarían a garantizar el cumplimiento de los objetivos institucionales, mejorar los servicios que ofrecen y la calidad en la gestión de la información. Por lo anterior, al momento de la investigación se planteó como objetivo general: realizar un diagnóstico de las necesidades de información de las personas usuarias del Sistema de Bibliotecas de la Organización para Estudios Tropicales (OET) para el mejoramiento de sus servicios y productos de información.

\section{Breve referente teórico}

\subsection{Evaluación de bibliotecas}

Para Melnik y Pereira (2006), la evaluación es un procedimiento que le permite a las bibliotecas conocer la adecuación de sus servicios, sus utilidades, sus fallas, etc. La evaluación puede ser 
realizada intuitivamente o de modo sistemático. Por lo general, debe responder a las siguientes preguntas: ¿qué servicios se deben prestar?, ¿se están ofreciendo todos los servicios necesarios?, ¿se está brindando algún servicio que no se debe ofrecer?, ¿se presta el servicio de la manera más eficiente posible? Y de no ser así, ¿cuáles son las causas y que se puede hacer para remediar el problema?

En otra definición mencionada por Di Domenico (2010, p. 81) citando a Arriola, se dice sobre la evaluación que:

Es un proceso sistemático que nos facilita determinar el grado de eficacia, economía y eficiencia de ciertas actividades; además nos requiere emitir un juicio de valor sobre aquello que se evalúa. Permite articular de forma cualitativa y cuantitativa el grado de cumplimiento de los objetivos marcados por la biblioteca, especialmente definidos en términos de necesidades de los usuarios, e indica su adecuación a las acciones y programas que fueron planificados por la biblioteca.

Además, Melnik y Pereira (2006) mencionan que existe una evaluación de tipo diagnóstico o inicial. Esta comienza con un proceso de planificación, y más que una evaluación, viene a ser un análisis de la situación inicial.

\subsection{Necesidades de información}

En cualquier ámbito en el que se desenvuelva el ser humano requerirá de información, ya sea para su recreación, para sus investigaciones, para la resolución de problemas cotidianos, o para sus negocios. De la necesidad se dice que "es algo abstracto que puede o no ser perceptible y en cuya manifestación entran en juego aspectos de carácter psicológico, afectivo y cognitivo" (Rojas Gutiérrez, 1998, p. 55).

Para González Solano: "Las necesidades de información son una propiedad inalienable de la naturaleza humana, y son las unidades de información - llámense bibliotecas, centros de documentación, centros de información, etcétera- las encargadas del estudio de esta cualidad" (2011, p. 51). Dado que esta es la única forma de poder ofrecer un servicio o producto acorde a las necesidades de información. Aunado a esto, Calva González, citando a Verdugo, comenta que la satisfacción:

...es el hecho de dar solución a una duda o una dificultad, aquietar y convencer, con una razón eficaz, la duda o queja que se había formulado. En este contexto, se entiende la satisfacción como la razón, acción o modo con que se sosiega y responde enteramente a una queja, sentimiento o razón contraria. (2011, p. 16)

Como se ha mencionado anteriormente, es la persona usuaria la razón de ser dentro de las unidades de información, los servicios y productos deben estar planeados en función de sus intereses y necesidades de información. Pero una vez implementadas las distintas acciones, se debe dar un seguimiento a la satisfacción o insatisfacción de la clientela, y así, direccionar adecuadamente el quehacer de las bibliotecas. 


\section{Metodología}

Esta investigación se desarrolló dentro del paradigma positivista, "el propósito de la investigación en este paradigma es buscar generalizaciones libres de contexto, leyes y explicaciones (nomotéticas): deductiva, cuantitativa, centrada en semejanzas" (Barrantes, 2000 , p. 60). Se trabajó bajo este tipo de paradigma, ya que buscó encontrar un patrón a seguir, una semejanza, una explicación.

El enfoque fue cuantitativo, porque es una concepción global positivista, que busca causas de los fenómenos, utiliza técnicas experimentales, aleatorias, de análisis, estadísticas, estudios de muestra. Sobre el enfoque cuantitativo Bernal Torres menciona:

...se fundamenta en la medición de las características de los fenómenos sociales, lo cual supone derivar de un marco conceptual pertinente al problema analizado, una serie de postulados que expresen relaciones entre las variables estudiadas de forma deductiva. Este método tiende a generalizar y normalizar los resultados. (2006, p. 57)

El tipo de investigación es descriptiva, dado que pretende diagnosticar la situación del Sistema de Bibliotecas de la OET y, por ende, proponer mejoras a su funcionamiento, según Bernal Torres:

En tales estudios se muestran, narran, reseñan o identifican hechos, situaciones, rasgos, características de un objeto de estudio o se diseñan productos, modelos, prototipos, guías, etcétera. Pero no se dan explicaciones o razones del porqué de las situaciones, los hechos, los fenómenos, etcétera. (2006, p. 112)

\subsection{Sujetos y fuentes de información}

El tiempo de estudio se limitó al periodo de marzo a julio del 2013.

\section{Sujetos}

Los sujetos de esta investigación fueron:

- Personas usuarias: que visitaron físicamente la biblioteca central.

- Personas usuarias virtuales: en este grupo se concentran 3 categorías, las personas que solicitaron información a través del Sistema de Información y Documentación Agropecuario de las Américas (SIDALC), quienes solicitaron información por medio del teléfono y el correo electrónico.

- Estudiantes y docentes de los cursos de la OET. En pregrado, Global Health; Tropical Biology (Summer-Sring); Native American and Pacific Islander Research Experience in 
Costa Rica (NAPIRE); y Research Experience for Undergraduates in Costa Rica (REU). En posgrado: Inquiry in rainforests: an in-Service Program for Teachers; Tropical Biology: an ecological approach; y Ecology \& Conservation of Neotropical Rivers.

- El personal de la OET: según el departamento de recursos humanos de la OET, su personal se encuentra clasificado en las siguientes categorías: operativo, proyectos y administrativos. Por tanto, para esta investigación se trabajó únicamente con las personas que se encontraban en las categorías de administrativo y proyectos. Se envió el cuestionario a un total de 80 personas.

- La encargada del sistema de bibliotecas.

- Las tres personas responsables de las bibliotecas en las estaciones biológicas.

- El coordinador del área de manejo de información.

- La directora general de la OET.

- La directora científica de la OET.

\section{Universo}

Con respecto a las personas usuarias a estudiar, se trabajó con la totalidad de la comunidad, es decir todo el universo. Este está constituido por 343 personas, articulado de la siguiente forma:

- 28 personas usuarias presenciales.

- 27 personas usuarias que solicitan información por correo electrónico o teléfono.

- 40 personas usuarias del servicio SIDALC.

- 142 estudiantes y 26 docentes de los cursos OET.

- 80 personas que trabajan en la OET.

\section{Fuentes}

Para el desarrollo de esta investigación se llevaron a cabo búsquedas exhaustivas, las cuales se dieron especialmente en bases de datos del SIBDI, el SIDUNA y otras bases como Teseo, Dialnet, Scirus, E-Lis, Ebsco, Proquest y Lista. Se dio prioridad a la consulta de libros, trabajos finales de graduación y artículos de revistas. También, se consultó los archivos institucionales de la OET, documentos propios del sistema de bibliotecas, así como las estadísticas y sus bases de datos.

\subsection{Variables: definición e instrumentalización}

Para responder a cada uno de los objetivos planteados en la investigación se identificaron variables, para las cuales fue necesario la elaboración de instrumentos de recolección. En el cuadro 1 se describe la organización de variables con respecto al objetivo específico. 


\section{CUADRO 1}

Objetivos y variables de investigación

\begin{tabular}{|c|c|c|}
\hline Objetivo & Variable & Instrumentalización \\
\hline $\begin{array}{l}\text { Identificar el perfil de los } \\
\text { usuarios y las usuarias del } \\
\text { Sistema de Bibliotecas de } \\
\text { la OET. }\end{array}$ & $\begin{array}{l}\text { Perfil de } \\
\text { personas } \\
\text { usuarias }\end{array}$ & $\begin{array}{l}\text { Cuestionario que se aplicó a los } 4 \\
\text { diferentes estratos de la comunidad total de } \\
\text { personas usuarias del Sistema de } \\
\text { Bibliotecas de la OET. }\end{array}$ \\
\hline $\begin{array}{l}\text { Determinar las necesidades } \\
\text { de información de las } \\
\text { personas usuarias del } \\
\text { Sistema de Bibliotecas de } \\
\text { la OET. }\end{array}$ & $\begin{array}{l}\text { Necesidades } \\
\text { de } \\
\text { información }\end{array}$ & $\begin{array}{l}\text { Cuestionario que se aplicó a los } 4 \\
\text { diferentes estratos de la comunidad total de } \\
\text { personas usuarias del Sistema de } \\
\text { Bibliotecas de la OET. }\end{array}$ \\
\hline $\begin{array}{l}\text { Valorar el uso que hacen } \\
\text { las personas usuarias de } \\
\text { los servicios y los } \\
\text { productos de información } \\
\text { que brinda el Sistema de } \\
\text { Bibliotecas de la OET. }\end{array}$ & Uso & $\begin{array}{l}\text { Cuestionario que se aplicó a los } 4 \\
\text { diferentes estratos de la comunidad total de } \\
\text { personas usuarias del Sistema de } \\
\text { Bibliotecas de la OET. }\end{array}$ \\
\hline $\begin{array}{l}\text { Identificar el nivel de } \\
\text { satisfacción de las } \\
\text { personas usuarias del } \\
\text { Sistema de Bibliotecas de }\end{array}$ & $\begin{array}{c}\text { Nivel de } \\
\text { satisfacción }\end{array}$ & $\begin{array}{l}\text { Cuestionario que se aplicó a los } 4 \\
\text { diferentes estratos de la comunidad total de } \\
\text { personas usuarias del Sistema de } \\
\text { Bibliotecas de la OET. }\end{array}$ \\
\hline
\end{tabular}

\subsection{Descripción de los instrumentos para la recolección de la información}

Se aplicó un cuestionario (Anexo), tanto de forma electrónica como de forma impresa; estuvo dirigido a las personas usuarias del Sistema de Bibliotecas de la OET. Este cuestionario tuvo que ser traducido, ya que algunas personas no hablaban o dominaban el español. El programa utilizado para el cuestionario electrónico fue Survey Monkey. De acuerdo con los objetivos, el cuestionario contempló los siguientes ejes:

- Perfil de la persona usuaria

- Necesidades de información

- Satisfacción

- Uso de los servicios y productos de información

Con la finalidad de poner a prueba el cuestionario, una vez elaborado se sometió a una prueba piloto, aplicándolo a cuatro funcionarios de la OET, dos usuarios presenciales y un profesor de los cursos de la OET. Además, se les pidió a dos colegas que lo revisaran.

Finalizada esta prueba piloto, se le hicieron diferentes modificaciones, correcciones y mejoras al cuestionario y se fusionaron algunas preguntas, pasando de 41 preguntas a 34 preguntas. 
"De este modo, el cuestionario quedó conformado por diecisiete preguntas de selección única, nueve preguntas de selección múltiple y ocho preguntas abiertas.

El cuestionario se aplicó de forma personal e impresa a cada persona que visitó la biblioteca. A estudiantes y docentes de los cursos de la OET, a las personas usuarias virtuales y al personal de la OET se les aplicó el cuestionario electrónico.

En abril del 2013, se inicia con el envío del cuestionario electrónico. Con la intención de lograr la mayor cantidad de respuestas, la aplicación del cuestionario electrónico se dio de la siguiente forma:

Para el personal de la OET:

a- Se envió el cuestionario electrónico.

b- Se esperó 4 días y se volvió a enviar la solicitud.

c- Se esperó 3 días y se volvió a enviar la solicitud.

d- A la semana se volvió a enviar.

Para estudiantes y docentes cursos OET:

a- Al finalizar cada curso se envió el cuestionario.

b- A los 4 días se volvió a enviar la solicitud.

c- A la semana se volvió a enviar la solicitud.

Para los usuarios y las usuarias virtuales:

a- Se envió el cuestionario.

b- Se esperó 4 días y se volvió a enviar la solicitud.

c- A la semana se volvió a enviar la solicitud.

Este método del uso de correo electrónico fue validado por el estadístico de la Escuela de Bibliotecología y Ciencias de la Información, el profesor Roger Bonilla. Sobre los cuestionarios, Calva González (2004) señala que estos tienen diversas modalidades, tales como: con preguntas cerradas, con preguntas abiertas, combinación de las anteriores, con escalas, aplicarlo directamente (podría ser una entrevista), o enviarlo por correo postal o electrónico. Con respecto al uso de las nuevas tecnologías en la recolección de información, Bernal Torres afirma sobre Internet que "no existe duda sobre las posibilidades que hoy ofrece Internet como una técnica de obtener información; es más, se ha convertido en uno de los principales medios para recabar información" (2006, p. 177).

\section{Resultados}

Seguidamente se presentan los resultados de la investigación organizados por variables, para lograr una mejor exposición de la información. Es importante aclarar que en los resultados que se presentan en los gráficos y en los cuadros se varía la cantidad de personas encuestadas, 
"debido a que algunas preguntas presentaban filtros o bien no aplicaba para la totalidad de los sujetos de investigación.

\subsection{Perfil de usuario}

Para esta variable, se recolectó información de importancia dentro del público que hace uso del Sistema de Bibliotecas de la OET, se contemplaron las siguientes características: sexo, nacionalidad, edad, idioma, grado académico, tipo de persona usuaria y la actividad a la que se dedica, incluyendo si estudian o no y en cual institución lo hacen, cual carrera cursan, si trabajan o no y la profesión y el puesto de trabajo. Para recolectar esta información, se definieron 5 grupos de edades, a saber: primer grupo, de 17 a 26 años; segundo grupo, de 27 a 36 años; tercer grupo, de 37 a 46 años; cuarto grupo, de 47 a 56 años y quinto grupo, mayores de 57 años. La mayor concentración del grupo etario se dio de 17 a 26 años de edad, con un total de 130 personas (40\%). El segundo conformó un 35\% de la población encuestada; el tercero recogió un $9 \%$, el cuarto grupo un $10 \%$ y el quinto un $6 \%$. De este modo, el $84 \%$ de las personas en estudio se encontraban entre los 17 y 46 años de edad, una población joven, y un $16 \%$, de 47 años en adelante.

Del total de la población en estudio, un 56\% correspondió a las mujeres, es decir 182. El restante $44 \%$ correspondió a los hombres. Con relación a la nacionalidad de las personas encuestadas, hubo una variedad importante de orígenes geográficos. Es importante mencionar que una de las personas encuestadas dijo tener dos nacionalidades, la colombiana y la española. Solo una persona se abstuvo de responder.

El $74 \%$ de las personas encuestadas (327) se encontraron entre dos nacionalidades, la costarricense con 114 personas (35\%) y la estadounidense con 129 (39\%). Este dato podría estar influenciado por el hecho de que la OET se promueve con mayor énfasis en estos dos países. Cuenta con dos oficinas administrativas, una en Estados Unidos, en la Universidad de Duke, y otra en Costa Rica; además en este último país se encuentran 3 estaciones biológicas pertenecientes a esta organización. Le siguieron en la lista nacionalidades como: colombiana con 15 personas; nicaragüense con 10, brasileña con 8; salvadoreña y argentina con 6 y 5 respectivamente; mexicana y peruana con 4 personas cada una; boliviana, canadiense, cubana, hondureña y puertorriqueña con 3 cada una. Hubo una opción de otras nacionalidades que albergó a 17 personas; se mencionaron países como Panamá, Islas del Pacífico y Ecuador, con dos personas cada país. Venezuela, Filipinas, Trinidad y Tobago, España, Haití, Hawaii, Guatemala, India, China e Inglaterra con una persona cada uno.

Es importante destacar que el $83 \%$ (274 personas) del total de la población en estudio dominaba el idioma inglés. Este hecho tiene una fuerte relación con el idioma principal de las colecciones de las bibliotecas de la OET: el inglés; esta lengua, además, es en la que mayormente se publica en el mundo de la ciencia, siendo las bibliotecas de la OET, unidades de información especializadas y científicas.

En su base de datos más sobresaliente, BINABITROP Costa Rica, el $60 \%$ de la literatura está en idioma inglés, el $37 \%$ en español, y el restante $3 \%$ en otros 10 idiomas. En el catálogo el $19 \%$ de la literatura está en español y el $78 \%$ en inglés. Es muy significativo el hecho de que la 
"mayoría de su público domine los dos idiomas de mayor presencia en las colecciones del Sistema de Bibliotecas, siendo esto una muestra de que el idioma inglés no está representando una barrera para quienes utilizan las unidades de información de la OET.

Los resultados muestran tres concentraciones importantes en cuanto a educación: bachiller 85 personas (26\%), máster 73 personas (22\%) y doctorado con 62 personas (19\%), para un total de 220 personas. Las otras 3 concentraciones menores fueron personas que se encontraban cursando el bachillerato universitario, ya tenían una licenciatura o un diplomado.

Esto permite observar que la mayoría, 323 personas, contaban con educación universitaria o un nivel superior a este. Se trata de una característica importante, dado que las bibliotecas de la OET por sus colecciones especializadas, tienen principalmente como público meta estudiantado universitario y personas que se dedican a la investigación.

Las 4 personas que se encontraron con grados académicos distintos al universitario son parte del personal de la OET: un guía naturalista, con secundaria completa; dos guías naturalistas y un practicante, con secundaria incompleta. Solo una persona no respondió (pregunta 5).

En la figura 1 se observa que el mayor grupo de personas se ubicó dentro de la categoría de alumnado de los cursos de la OET con un 31\%. Todos los tipos de personas usuarias mencionadas se encontraron dentro del público meta que actualmente está definido para el Sistema de Bibliotecas de la OET.

En la categoría otros, se localizaron personas que no se pudieron ubicar en las opciones dadas, entre ellos 4 profesores, 3 guías naturalistas, 2 profesionales interesados en la temática, un extensionista del sector público y un practicante. Una persona no respondió. Cabe hacer la aclaración de que las dos primeras categorías de personas que presenta la figura 1 son diferentes: la primera hace referencia a las personas que han matriculado algún curso de la OET y la segunda a estudiantes externos a la OET.

Del total de la población en estudio, 194 personas afirmaron estar estudiando, para un 59\%; un $41 \%$ (133 personas) no se encontraba estudiando. Con este dato sobresale el hecho de que a pesar de tener un nivel de educación alto, las personas usuarias mantienen activa su preparación académica. 171 personas indicaron la carrera o área de estudio, para un total de 44 carreras de estudio; una persona se abstuvo de responder. Las carreras con mayor mención fueron Biología, Ecología y Manejo de recursos naturales con 64, 17 y 13 menciones respectivamente. 
FIGURA 1

Distribución relativa de las personas usuarias del Sistema de Bibliotecas de la OET según su tipo

$\mathrm{n}=327$

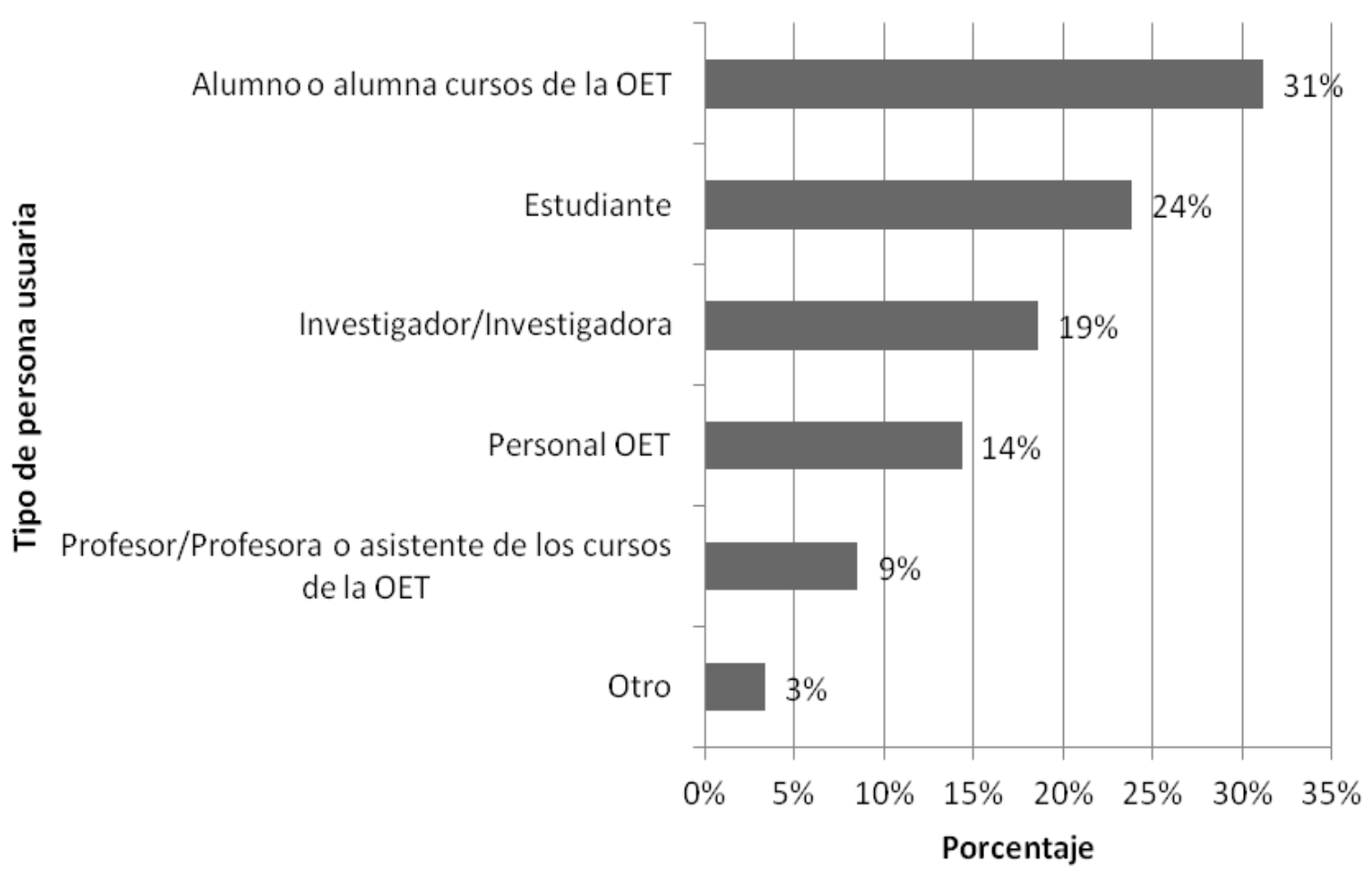

\subsection{Necesidades de información}

La información recopilada en los instrumentos brinda datos importantes para determinar la variable de necesidades de información de quienes utilizan el Sistema de Bibliotecas de la OET. Se indicaron las existencias o carencias que se encuentran en el sistema a partir de las respuestas.

Para la obtención de este dato, respondieron a la pregunta 14, 265 personas: 258 (56\%) utilizaron internet, $163(35 \%)$ utilizaron las bibliotecas y 40 personas $(9 \%)$ marcaron la opción otros. En esta pregunta, si la persona seleccionaba la opción de "otros" se le solicitaba especificar el medio por el que consumían la información, los medios mencionados fueron: bases de datos especializadas, especialistas en el tema, bibliotecas personales, libros, personas y revistas, autores, BINABITROP Costa Rica, coordinadores de cursos e investigadores de OET, directorio telefónico, registros públicos de instituciones, textos de clase y trabajo de campo.

En cuanto al motivo por el cual las personas usuarias requieren información del Sistema de Bibliotecas, encontramos que responden 195 personas. Esta cifra disminuye ya que solo la debían responder las personas que sí visitaban las bibliotecas de la OET. Es importante tomar 
en cuenta que de las personas entrevistadas no todas han asistido a las bibliotecas o solicitado algún servicio de información, tal es el caso del personal, o del alumnado de los cursos de la OET. El detalle de la visitación se puede observar con mayor detalle en la figura 2:

\section{FIGURA 2}

\section{Distribución relativa de las personas usuarias del Sistema de Bibliotecas} de la OET según la actividad por la que requerían información*

$$
n=195
$$

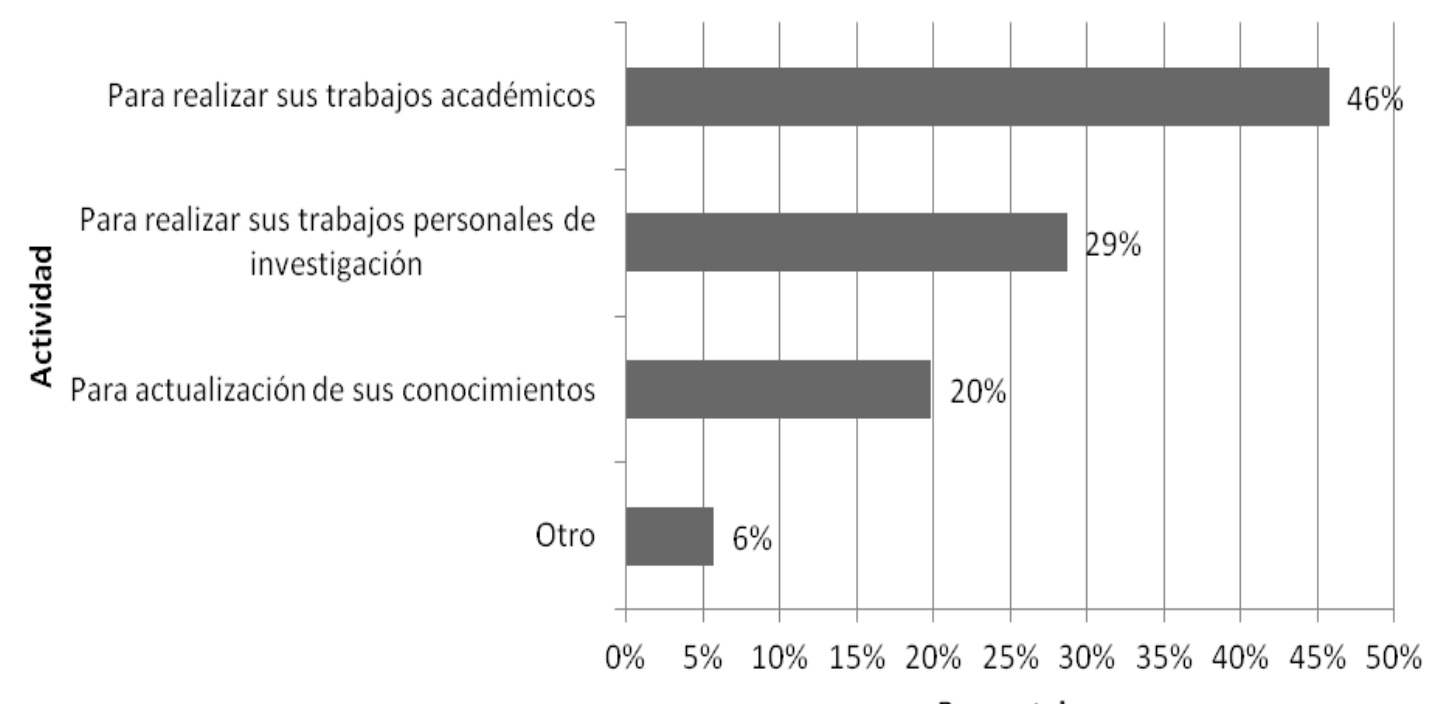

*Los datos corresponden al total de menciones y no de personas encuestadas.

En la opción de otros se les pidió indicar el detalle, se dieron 17 especificaciones. 9 aspectos hacían referencia a: razones de trabajo, apoyo a estudiantes, aprendizaje general, "desde que era estudiante la visito", espacio de estudio, evaluación del estado de la conservación, hay aire acondicionado en la biblioteca, "información que me han solicitado amigos que no tienen acceso a las bibliotecas de la OET", para transferir a productores.

En cuanto a la pregunta 19, sobre la utilidad del material brindado en el Sistema de Bibliotecas, un $95 \%$ respondió positivamente y $5 \%$ de forma negativa, o sea que no le fue útil para su gestión. Esta pregunta tenía un filtro y debía ser respondida únicamente por aquellas personas que visitaron las bibliotecas de la OET; por esta razón el número de respuestas disminuye, en este caso es de 184 personas que sí responden. La pregunta tenía la opción de manifestar comentarios, se recibieron 28 en total. A continuación se presentan 3 ejemplos de las opiniones emitidas:

"Hay muchos artículos útiles en BINABITROP, pero estos algunas veces no están accesibles al público en computadoras fuera de la OET".

"Si [sic] porque la información veraz no siempre está disponible en internet o es difícil de encontrar". 
"Muchos libros no estaban en el lugar correspondiente por lo que fue difícil encontrarlos".

En cuanto a las respuestas a la pregunta 21, los comentarios recibidos apuntan 3 aspectos: mayor divulgación, aumento de texto completo y más libros sobre temas en particular. Contestaron 191 personas y se recibieron 110 comentarios. De estas 191, en su mayoría, 188 (98\%) opinaron que las bibliotecas de la OET si son valiosas. En esta pregunta el número de respuestas disminuye porque debía ser respondida solo por aquellas personas que visitaran las bibliotecas de la OET.

"Información pertinente fácil de ubicar y con posibilidades de ampliar consultas. Mucha de esa información prácticamente solo allí se ubica. Además de la recopilación en específico de una gran variedad de temas y la revisión exhaustiva que se hace, además de la atención que siempre ha sido oportuna y amable".

"Históricamente, fueron los únicos lugares donde estudiantes costarricenses tenían libre acceso a libros y material publicado actualizado. Actualmente, constituyen importantes centros desde donde manejar información suplementaria que puede servir tanto a estudiantes como a visitantes de comunidades locales (en el caso de bibliotecas de las estaciones)".

"Por su aporte al conocimiento científico, al conocimiento humano, porque recopilan datos de cursos, talleres etc [sic] que se imparten en la OET y a partir de ahí realizan producciones de un gran aporte bibliográfico".

"Por supuesto, porque sin importar en que parte de mundo se encuentren facilita a muchas personas satisfacer su necesidad de información, ya sea mediante libros, en forma digital o a través de Internet".

Los 110 comentarios fueron positivos. En ellos se destacan las colecciones exclusivas, científicas y especializadas con que cuentan las bibliotecas, el acceso electrónico desde cualquier parte del mundo, lo útil que es BINABITROP Costa Rica y otras bases de datos.

En cuanto a las recomendaciones de mejora, 80 personas emitieron su criterio, para un total de 106 sugerencias. En el Cuadro 2 se puede observar una síntesis de las opiniones que tuvieron mayor concentración.

Otras sugerencias que no se incluyen en el cuadro 2 fueron: ampliar horario, mejorar la conservación del material (humedad y control sobre préstamos), mejorar las computadoras, remodelación, seguir mejorando y mantenerse al día con las tecnologías. Estas sugerencias tuvieron 4 menciones cada una. Aparecieron también recomendaciones que obtuvieron dos menciones cada una: ampliar cobertura geográfica en las bases de datos, asociarse a otras universidades e instituciones, aumentar el personal, bibliotecas abiertas al público, estoy satisfecha, más ventilación, mayor organización, mejorar la iluminación, seguir alimentando BINABITROP y suscripción a revistas en línea. 
Las opiniones individuales fueron: aumentar bases de datos, ayuda de estudiantes de Bibliotecología de la Universidad de Costa Rica (UCR) y la Universidad Nacional de Costa Rica (UNA), estudios bibliométricos para las bibliografías de las estaciones, horario nocturno en Biblioteca CRO, la amabilidad, más libros sobre plantas, mejorar en general, ninguna, no mover más la biblioteca de LS, personal que atienda en LS y PV, talleres para el personal.

\begin{tabular}{|c|c|}
\hline \multicolumn{2}{|c|}{$\begin{array}{c}\text { CUADRO } 2 \\
\text { Sugerencias emitidas por las personas usuarias del } \\
\text { Sistema de Bibliotecas para mejorar algún aspecto en sus } \\
\text { unidades de información* } \\
n=80\end{array}$} \\
\hline Sugerencia & Menciones \\
\hline Mayor divulgación y promoción & 16 \\
\hline Actualizar las colecciones & 10 \\
\hline Digitalizar la colección & 9 \\
\hline Acceso libre & 8 \\
\hline Bases de datos más amigables & 7 \\
\hline Más servicios e interacción en línea & 5 \\
\hline
\end{tabular}

A la pregunta 24 sobre la contribución de las unidades de información con la misión y objetivos de la OET, respondieron un total de 204 personas y se recibieron un total de 75 comentarios. Esta interrogante estaba dirigida solo para aquellas personas que sí visitaron las bibliotecas de la OET.

De estos comentarios, 63 resaltaron las razones por las cuales las bibliotecas de la OET contribuían al cumplimiento de la misión de esta organización. Todos estos comentarios son muy positivos y destacan el quehacer de estas unidades de información, algunos de los comentarios más sobresalientes fueron:

"No sólo se le da cobertura a revistas de acto impacto en inglés sino también a muchas revistas locales en español/portugués que son la base para esos estudios macro que permiten luego generalizar. Para los estudiantes de la OET, esta amplitud de registro bibliográfico es vital durante su formación académica".

"La de CRO pues es un centro de difusión de la información que es difícil de obtener si no se tiene acceso a bases de datos en línea."

"Porque compila toda la información que se produce en las estaciones de la OET y otros lugares del TROPICO, muchos investigadores producen investigaciones, las publican y estas se suben a bases de datos generalmente estadounidenses, las cuales cobran por bajar los artículos y se convierten en inaccesibles para los estudiantes latinos que no tiene acceso a esa bases de datos." 
"También, se realizó una pregunta en cuanto a la razón de no visitar las bibliotecas de la OET (pregunta 23). 4 personas comentaron que no utilizaban estas bibliotecas; 2 personas manifestaron su malestar con respecto a la ubicación del material y el catálogo en línea; y 6 personas, además de manifestar en su comentario que las bibliotecas sí contribuyen a la misión de la OET, ofrecieron algunas recomendaciones para mejorar:

"En el quehacer científico es parte fundamental la divulgación de la investigación, el sistema contribuye a esto pero veo que se le debe dar más divulgación (que más personas sepan que existe el sistema)."

"Nuestra institución es primeramente académica. La biblioteca es una herramienta fundamental en el desarrollo de actividades de educación e investigación. Desgraciadamente, no todos a lo interno o a lo externo de la OET ven el valor de estos centros de documentación. Eso supone un reto: cómo hacer que externo [sic] de la OET ven [sic] el valor de estos centros de documentación. Eso supone un reto: cómo hacer que la biblioteca y actividades relacionada con la consecución, almacenamiento y acceso de documentos sea aceptado como uno de los grandes servicios que brinda la OET."

"Pero falta mucho más deben de contribuir a una verdadera "democratización de la información", pero el trabajo con el acceso por manera de PDF ayuda en este sentido."

"Tuve una pregunta de investigación específica mientras pasaba tiempo en la biblioteca leyendo los libros relevantes. Definitivamente aprecio su presencia en Las Cruces. Sin embargo, los libros no eran libros electrónicos. ¿Está la OET estudiando si invierte más recursos en línea en sus bibliotecas?"

"Digitalizar artículos no parece ser una prioridad y muchas veces una bibliografía (tampoco) y sólo el resumen disponible no es suficiente información, algunos artículos más viejos están en revistas obscuras que son indisponibles, por lo que el artículo está efectivamente "muerto" para recientes investigaciones (se refiere a que son copias y que la fotocopia o impresión no es de muy buena calidad)."

En general los comentarios emitidos por las personas usuarias del Sistema de Bibliotecas de la OET apuntaron los siguientes aspectos: divulgan y recopilan las investigaciones realizadas en la OET, poseen información sobre las áreas donde se ubican las estaciones, fortalece los objetivos de investigación y educación, y permiten la consulta de otra información científica que no podría ser accesible por otros medios debido a su elevado costo económico.

El horario del Sistema de Bibliotecas fue otra pregunta, esta de opción múltiple (pregunta 25). A ella, respondieron un total de 212 personas. En su mayoría las personas usuarias prefieren un horario de jornada continua (24\%) para las bibliotecas de la OET, seguido por un horario nocturno con un $20 \%$, horario vespertino un $19 \%$, durante la mañana $14 \%$, sábados $13 \%$ y domingos 9\%. Actualmente la biblioteca central tiene un horario de lunes a viernes de 8 a.m. a 
5 p.m. y las bibliotecas en las estaciones tienen un horario más flexible, e incluso si se requiere pueden permanecen abiertas durante los fines de semana o en la noche.

Los datos muestran que un $66 \%$ de las personas encuestadas prefiere la información tanto en formato impreso como digital y un $32 \%$ que solamente de forma digital. Es decir que un $98 \%$ de las personas usuarias se inclinan por consultar la información de forma digital, esto a partir de las respuestas a la pregunta 26.

Un hecho interesante a contrastar con estos datos es que, según las observaciones realizadas y las entrevistas al personal del Sistema de Bibliotecas y del Área de Manejo de Información de la OET, se está trabajando fuertemente en digitalizar las colecciones y en adquirir los documentos de forma digital. Por ejemplo, la base de datos BINABITROP Costa Rica tiene un total de 39689 registros, de los cuales el 45\% están disponibles en texto completo. En ese sentido, el poder ofrecer las colecciones de forma digital es una meta muy bien orientada que se está llevando a cabo dentro del Sistema de Bibliotecas de la OET.

Sobre la actualidad de las colecciones, 172 personas respondieron y emitieron su opinión (pregunta 29). De ellas, 93 indicaron que estas son actuales y 37, muy actuales, para un $76 \%$ entre estos dos aspectos. Esta pregunta, a pesar de no tener ningún filtro, la responden solo 172 personas; esto posiblemente se deba al desconocimiento que tienen sobre el estado de los documentos de las unidades de información de la OET. Sería importante comparar esta percepción de las personas usuarias versus la realidad de las colecciones del Sistema de Bibliotecas de la OET mediante indicadores bibliométricos que determinen la obsolescencia, antigüedad y actualidad de estas.

Los cursos que la OET ofrece durante el año, mantienen sus propias colecciones de libros; estos son llevados a las giras de campo por parte del estudiantado. Uno de los ítemes del cuestionario preguntó a las personas si habían llevado algún curso de la OET, un total de 146 personas dijeron haberlo hecho. De estas personas, a la pregunta 31, de si durante el curso se les había brindado información sobre las bibliotecas de la OET respondieron 141 personas; de ellas 109 (77\%) dijeron que sí.

De las 146 personas que afirmaron llevar un curso de la OET, según la pregunta 30, solamente 125 respondieron. De estas, 112 (90\%) señalaron que sí les fueron útiles los libros (pregunta 32). A la pregunta 33, 118 personas respondieron que los libros no fueron de utilidad, e indicaron: como primera razón que toda la información la encontraron en Internet (43\%); la segunda razón fue que no habían libros sobre su tema de investigación (31\%); la tercera razón fue que toda la información la encontraron en bases de datos de su universidad (11\%); la cuarta razón fue que estaban muy desactualizados (11\%), la quinta razón fue que el profesor les dio toda la literatura (2\%); la sexta razón fue que el curso no exigió libros (2\%), y la sétima razón fue pocas copias (1\%). En la categoría de otros, las 4 razones mencionadas fueron:

"Inconsciente de que hubiera información disponible. Utilizo Internet por costumbre."

"Estaban desorganizados en la estantería." 
"Muchos de los libros no estaban disponibles. Varios libros nuevos pero relevantes, no estaban incluidos en la biblioteca del curso".

"Nunca nos asignaron lecturas de los libros que teníamos que traer y nunca nos informaron sobre los servicios de la biblioteca, por lo que hice más investigación en línea."

A la pregunta 28, sobre servicios y productos recomendados, 67 personas emitieron sus comentarios. En el Cuadro 3 se observa una síntesis de los 12 aspectos que más indicaron las personas usuarias. Las opiniones apuntan aspectos importantes, como ofrecer las colecciones digitales, facilitar el acceso a otras bibliotecas virtuales, mejorar la comunicación virtual y mayor guía y comunicación con el estudiantado nuevo.

\section{CUADRO 3}

Distribución de las personas usuarias del Sistema de Bibliotecas de la OET según los servicios y productos que les gustaría que las bibliotecas le ofrecieran*

$$
\mathrm{n}=67
$$

\begin{tabular}{lc}
\multicolumn{1}{c}{ Opinión } & Menciones \\
\hline Disponibilidad de documentos digitales & 11 \\
Más información en temas específicos & 8 \\
Todo está bien así & 6 \\
Acceso a bases de datos en texto completo & 6 \\
Estación de café & 5 \\
Material audiovisual (fotos, documentales, mapas, DVD, & 4 \\
CD) & 3 \\
Boletines informativos & 3 \\
Apertura al público & 3 \\
Guía en el uso de las bibliotecas y las búsquedas de & \\
información & 2 \\
Charlas, simposios, talleres de aprendizaje & 2 \\
Acceso a las bibliotecas digitales de las universidades & \\
sociales de la OTS & 2 \\
Préstamo interbibliotecario & \\
\hline *Las 12 primeras opiniones de un total de 39. Los datos corresponden al total de \\
menciones y no al de personas encuestadas.
\end{tabular}

\subsection{Valorar el uso}

La variable fue valorar el uso que hacen las personas usuarias de los servicios y productos de información que brinda el Sistema de Bibliotecas de la OET. La cantidad de personas que respondieron para cada biblioteca es Palo Verde $n=234$, La Selva y la Central $n=244$, Las Cruces $n=235$. A partir de estas cifras se elabora la figura . 
Las unidades más visitadas son la Central y La Selva, con 112 personas (46\%) cada una. La biblioteca de Las Cruces y Palo Verde con 77 (33\%) y 69 (29\%) personas respectivamente. En forma global los resultados mostraron que más del $50 \%$ de personas usuarias nunca visitaron de forma física las bibliotecas de la OET.

Es necesario resaltar que el Sistema de Bibliotecas tiene sus colecciones disponibles en Internet y el $47 \%$ de los registros están de forma digital. Por esto, se puede suponer que la cantidad de quienes la visitación de forma virtual es mayor, pero no hay un modo de asegurarlo. Se debe emplear un mecanismo para medir la visita virtual y las descargas de documentos.

La cantidad de personas que respondieron la pregunta 27, sobre si tenían conocimientos de servicios y productos varía dependiendo de cada uno de ellos, entre 195 a 214. La figura 3 demuestra que en su mayoría las personas desconocen los servicios del Sistema de la OET. Sin embargo, por los comentarios realizados, es posible que estén utilizando estos servicios o productos, pero no los conozcan por el nombre como tal.

Igual al punto anterior, las respuestas sobre la utilización de servicios y productos varían dependiendo del servicio o producto, entre 99 a 139 personas. En comparación con las personas que conocen estos servicios, al preguntárseles que si los utilizan el porcentaje disminuye gradualmente.

\subsection{Grado de satisfacción}

Para este punto la cantidad de respuestas a la pregunta 20, se redujo considerablemente para cada biblioteca y para cada aspecto evaluado. El número de personas que respondió varía entre 229 a 288. Este evento no representa problema, ya que hay algunos sectores de la población en estudio que nunca han visitado físicamente la biblioteca y en esta pregunta se evalúan aspectos muy específicos sobre las unidades de información.

\subsubsection{Grado de satisfacción de la Biblioteca Central de la OET}

En cuanto al grado de satisfacción en los servicios y productos de la Biblioteca Central de la OET, los resultados mostraron que más del $80 \%$ de las personas usuarias que visitan la biblioteca central se encuentran satisfechos o muy satisfechos con respecto a los aspectos evaluados. La Biblioteca Central es la que mejor grado de satisfacción presenta por parte de quienes la visitan, algunas de las posibles causas pueden ser: es la única biblioteca que cuenta con una persona especializada en Bibliotecología y a tiempo completo para la atención de solicitudes de información, es la unidad que presenta mejores instalaciones físicas y mejores condiciones climatológicas.

El grado de satisfacción con respecto a la biblioteca de La Selva, en todos los aspectos contemplados, varía. El $80 \%$ de las personas usuarias se encuentran satisfechas o muy 
satisfechas, excepto bases de datos que está por debajo del 80\%. El nivel de poco satisfechos se incrementa en comparación con la Biblioteca Central.

\section{FIGURA 3}

Distribución de las personas usuarias según conocimiento que tienen de los servicios y productos de información del Sistema de Bibliotecas de la OET

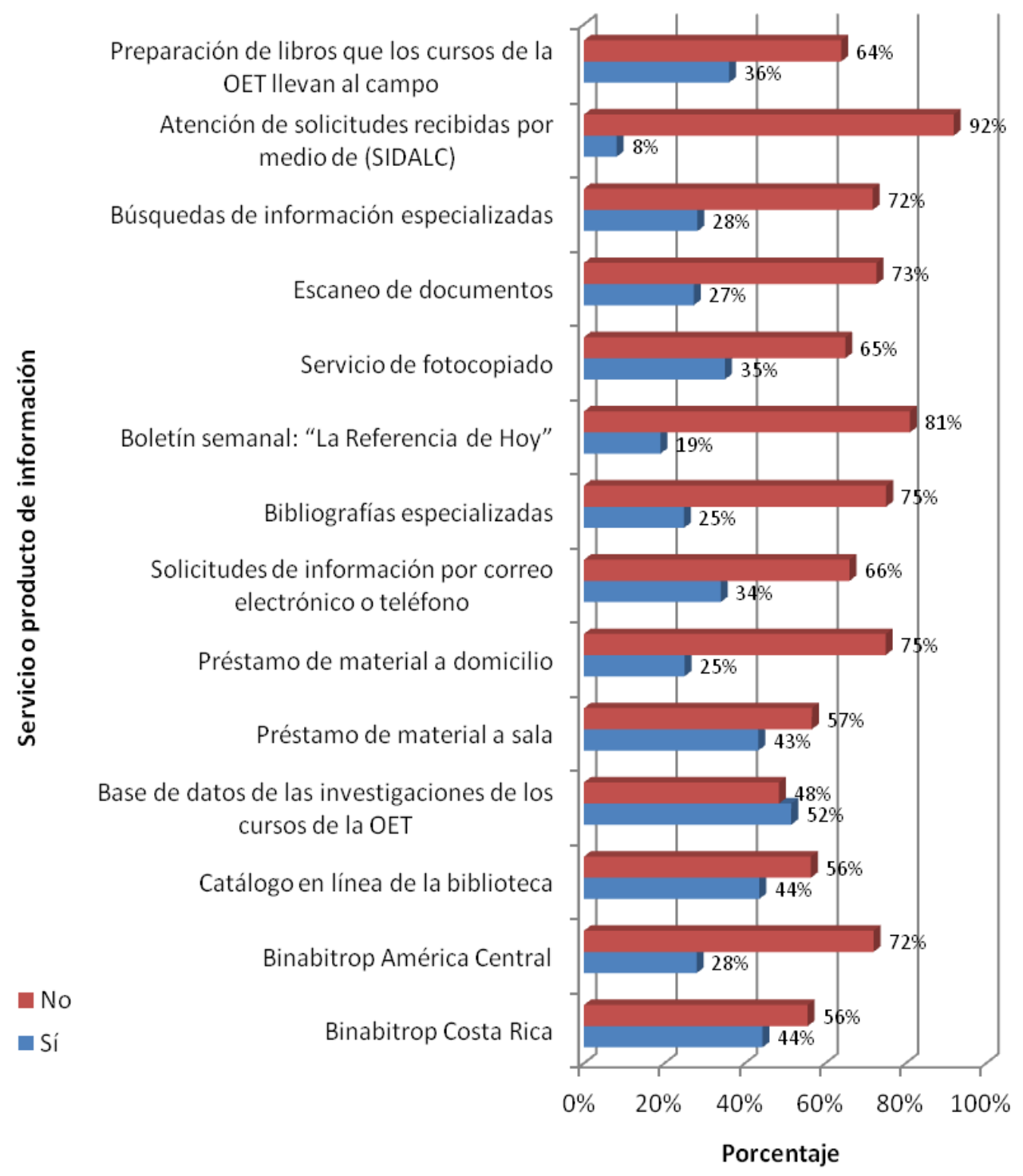

Se puede observar que más del $80 \%$ de las personas usuarias que visitan la biblioteca de Las Cruces se encuentran satisfechas o muy satisfechas con los diferentes aspectos evaluados. Igualmente, más del $80 \%$ de las personas usuarias que visitan la biblioteca de Palo Verde se encuentran satisfechas o muy satisfechas con los diferentes aspectos evaluados. Excepto en la atención brindada, que estuvo por debajo del $80 \%$. En esta última biblioteca se hace notable 
que en comparación con las otras bibliotecas incrementan los niveles de poco satisfecho e insatisfecho.

\section{Conclusiones}

Después de terminar esta primera experiencia de colaboración entre la Escuela de Bibliotecología y Ciencias de la Información y la Organización para Estudios Tropicales podemos concluir en términos de investigación que realizar trabajos colaborativos representa una gran riqueza para ambas partes. Esto se debe al aprendizaje adquirido, tanto en la temática de la biodiversidad como en el establecimiento de convenios de cooperación y la realización de metas conjuntas.

Con los resultados del diagnóstico se pudieron comprobar situaciones positivas y de mejora que posee el Sistema de Bibliotecas de la OET, por lo cual y como parte del Trabajo Final de Graduación, se elaboró una propuesta para el mejoramiento de los servicios y productos de información. Se espera que a partir de los resultados expuestos los servicios y productos que tiene el sistema puedan ser proyectados a la comunidad científica de una mejor manera y así satisfacer las necesidades de información que tienen sus personas usuarias.

A partir de los resultados obtenidos en la investigación se lograron identificar como conclusiones más importantes las que se presentan a continuación por variable. El orden de las variables es: perfil de personas usuarias, necesidades de información, uso y nivel de satisfacción.

Con respecto al perfil de personas usuarias, se establece que son personas entre los 17 a 36 años de edad, con un alto nivel de escolaridad, con buenos puestos de trabajo, residentes de países de toda América Latina, Estados Unidos y Canadá, con dominio del idioma inglés y el español, con acceso a la tecnología e interesadas en áreas como la Biología y temas afines. Se categorizaron en: alumnado, docentes y asistentes de los cursos de la OET, estudiantes universitarios, investigadores e investigadoras externos a la OET, personal administrativo y científico de la OET, coincidiendo con el que tiene definido actualmente el Sistema de Bibliotecas de la OET.

En lo relativo a las necesidades de información, se evidenció que las personas en la encuesta, cuando necesitaban de información, acudían en su mayoría a las búsquedas en Internet $(56 \%)$ y un $35 \%$ acude a diferentes bibliotecas. Las principales sugerencias y nuevos servicios mencionados por las personas usuarias fueron: procurar colecciones digitales, más información sobre algunos temas en específico, acceso a otras bases de datos, boletines informativos, accesibles vía Internet y con acceso gratuito, una mayor divulgación y promoción de las bibliotecas, bases de datos más amigables y mejorar el sistema de búsquedas, espacio para café, más servicios e interacción en línea, una mayor instrucción en cuanto al uso de los servicios y productos de información. En relación con el formato de los documentos preferido por las personas usuarias para consultar información se dieron los siguientes porcentajes: digital (32\%), impreso (2\%) y ambos (66\%). Sobre las colecciones de libros que los cursos de la OET llevan al campo, 146 personas afirmaron haber llevado un curso; y, de estas, 125 
respondieron a la pregunta sobre la utilidad de estos y 112 afirmaron que estos libros sí les fueron útiles. Entre las razones del por qué no les fueron útiles se encuentran: toda la información la encontraron en Internet o por medio de sus universidades, no habían libros sobre el tema de investigación que estaban desarrollando y la colección era muy desactualizada. Algunos comentarios emitidos apuntan la idea de que las bibliotecas de la OET se abran a personas externas a la institución, como las comunidades, escuelas y los colegios aledaños.

En cuanto al uso, la mayoría de la población en estudio no visita físicamente las bibliotecas de la OET. Entre el personal a cargo de estas unidades se tiene la creencia de que la visitación es mayor de forma virtual, ya que casi la mitad de los registros en BINABITROP CR se encuentran de forma digital y se reciben solicitudes por correo electrónico. Esto se puede comprobar por medio de los datos estadísticos para el 2013 que maneja la Biblioteca Central, donde se atendieron 644 consultas vía correo electrónico versus 204 consultas generadas de forma presencial.

Para el nivel de satisfacción, se encuentra que en general existe un alto nivel de satisfacción, obteniendo el grado más alto de las cuatro unidades de información la Biblioteca Central. El diagnóstico reveló que el perfil de usuarios y usuarias que tenía definido el Sistema de Bibliotecas de la OET coincidió con el del diagnóstico, así como las temáticas definidas para el desarrollo de colecciones concordó con las áreas de interés de las personas en estudio; esto quiere decir que en las bibliotecas de la OET han venido diseñando servicios y productos de información, desarrollo de colecciones y elaboración de planes de trabajo de forma adecuada, lo cual influye directamente en la satisfacción de las necesidades de información.

\section{Referencias}

Aguilar Zumbado, S. (2014). Diagnóstico del Sistema de Bibliotecas de la Organización para Estudios Tropicales (OET), periodo 2013: Propuesta para el mejoramiento de sus servicios y productos de información (tesis de licenciatura). Escuela de Bibliotecología y Ciencias de la Información, Universidad de Costa Rica, San José, Costa Rica.

Barrantes Echavarría, R. (2000). Investigación: un camino al conocimiento, un enfoque cualitativo y cuantitativo. San José, Costa Rica: EUNED.

Bernal Torres, C. (2006). Metodología de la investigación: para administración, economía, humanidades y ciencias sociales. México: Pearson Educación.

Calva González, J. J. (2004). Las necesidades de información: fundamentos teóricos y prácticos. México: UNAM, Centro Universitario de Investigaciones Bibliotecológicas.

Calva González, J. J. (2011). La satisfacción de los usuarios en las unidades de información: modelos y principios teóricos. En J. Lau (Comp.), Satisfacción de 
usuarios: evaluación integral de bibliotecas (pp. 15-28). Veracruz, México: Alfagrama.

Di Domenico, G. (2010). La gestión de la calidad en la biblioteca. En: Gestión y planificación en bibliotecas. Buenos Aires, Argentina: Alfagrama.

González Solano, J. A. (2011). Diseño participativo: un método para probar las percepciones de los usuarios. En J. Lau (Comp.), Satisfacción de usuarios: evaluación integral de bibliotecas (pp. 29-50). Veracruz, México: Alfagrama.

Lau, J. (comp). (2011). Satisfacción de usuarios: evaluación integral de bibliotecas. Veracruz, México: Alfagrama.

Melik, D. y Pereira, M. E. (2006). Bases para la administración de bibliotecas: organización y servicios. Buenos Aires, Argentina: Alfagrama.

Naciones Unidas. (1992). Convenio sobre la Diversidad Biológica. Recuperado de http://www.cbd.int

Rojas Gutiérrez, E. (1998). El usuario de la información. San José, Costa Rica: EUNED.

Rubio Liniers, M. C. (1999). Bibliometría y ciencias sociales. Revista AlBDA, 20(2), 138155.

Ruiz Vaca, J. O. y Martínez Arellano, F. F. (2011). Evaluación de los servicios bibliotecarios y de información. De los estudios de usuarios a la evaluación de la calidad de los servicios. En J. Lau (comp.), Satisfacción de usuarios: evaluación integral de bibliotecas (pp. 67-74). Veracruz, México: Alfagrama.

Stueart, R. D. y Moran, B. B. (1998). Gestión de bibliotecas y centros de información. Lleida: Pagès Editors, Barcelona: Diputació de Barcelona.

Ugalde Gómez, J., Herrera Villalobos, A., Obando Acuña, V., Chacón Chavarría, O., Vargas Del Valle, M., Matamoros Delgado, A., García Víquez, R. y Fuentes González, G. (2009). Biodiversidad y cambio climático en Costa Rica: Informe Final. Santo Domingo de Heredia: Instituto Nacional de Biodiversidad (INBio).

\section{Agradecimientos}

Deseamos expresar nuestros agradeciemientos al señor Oscar Madrigal Ovares, coordinador de Manejo de la Información de la OET, por su valiosa colaboración a este estudio. 


\begin{tabular}{|c|c|}
\hline $\begin{array}{l}\text { UNIVERSIDAD DE COSTA RICA } \\
\text { FACULTAD DE EDUCACIÓN } \\
\text { ESCUELA DE BIBLIOTECOLOGÍA Y } \\
\text { CIENCIAS DE LA INFORMACIÓN }\end{array}$ & $\begin{array}{c}\text { Cuestionario } \\
\text { Usuarias y usuarios del Sistema de } \\
\text { Bibliotecas de la Organización para } \\
\text { Estudios Tropicales }\end{array}$ \\
\hline \multicolumn{2}{|c|}{$\begin{array}{l}\text { Estimado-(a) usuario-(a): } \\
\text { El presente cuestionario tiene como objetivo recabar información sobre el Sistema de } \\
\text { Bibliotecas de la Organización para Estudios Tropicales. Los resultados de esta } \\
\text { investigación serán utilizados para el proyecto final de graduación "Diagnóstico del } \\
\text { Sistema de Bibliotecas de la Organización para Estudios Tropicales (OET)". Se } \\
\text { agradece su colaboración. Toda la información suministrada será confidencial y de } \\
\text { uso exclusivo para los objetivos de esta investigación. }\end{array}$} \\
\hline
\end{tabular}

\section{Parte. Perfil de usuario(a)}

1- Sexo:

a-

Femenino bMasculino

2- ¿Cuál es su nacionalidad?

aCostarricense

bEstadounidense

cOtra, especifique

3- ¿Cuál es su edad en años cumplidos?
a- Menor de 16 años
d- 37 a 46 años
b- 17 a 26 años
e- 47 a 56 años
c- 27 a 36 años
f- Mayor de 57 años

4- ¿Qué idiomas domina?
a-
Español
b- Inglés
c- Francés
d- Alemán
e- Otro, especifique

5- ¿Cuál es su último grado académico? 

a- __ Diplomado
b- ___ Cursando el bachillerato
c- Bachiller
d-___ Licenciado (a)
e-__ Máster
f-__ Doctorado
g-_ Otro, especifique

6- De las siguientes categorías, indique la que mejor se ajusta a su condición actual. (Marque solo una opción).

a-___ Estudiante externo (a) a la OET (Si marcó esta opción pase a la pregunta 8)

b-___ Alumno/Alumna de los cursos de la OET

c-___ Investigador/Investigadora

d-__ Personal administrativo de la OET

e-___ Profesor/Profesora o asistente de los cursos de la OET

f-___Bibliotecólogo/Bibliotecóloga

g-___ Otro, especifique

7- ¿Actualmente, se encuentra estudiando?

a-_ Sí b- ___ No

(Si su respuesta es negativa pase a la pregunta 10)

8- ¿En qué institución se encuentra estudiando?

9- ¿Cuál carrera o curso se encuentra estudiando?

10- ¿Actualmente está trabajando?

a- Sí b- No

(Si su respuesta es negativa pase a la pregunta 14)

11- ¿Cuál es su profesión?

12- ¿En qué institución trabaja?

13- ¿Qué puesto de trabajo ocupa?

\section{Parte. Necesidades de información}

14- Cuando necesita información, ¿a dónde acude?

(Puede marcar más de una opción). 

a- Internet
b- Bibliotecas
C- Otro, especifique

15- Para cada una de las bibliotecas de la OET, indique la frecuencia con que las visita.

\begin{tabular}{|c|c|c|l|l|l|c|}
\hline Bibliotecas & $\begin{array}{c}\text { Nunca la } \\
\text { he } \\
\text { visitado }\end{array}$ & $\begin{array}{c}\text { Una vez o } \\
\text { primer } \\
\text { visita }\end{array}$ & Regularmente & $\begin{array}{c}\text { Algunas } \\
\text { veces }\end{array}$ & $\begin{array}{c}\text { Pocas } \\
\text { veces }\end{array}$ & $\begin{array}{c}\text { Muy } \\
\text { pocas } \\
\text { veces }\end{array}$ \\
\hline $\begin{array}{c}\text { Biblioteca } \\
\text { Central }\end{array}$ & & & & & & \\
\hline La Selva & & & & & & \\
\hline Las Cruces & & & & & & \\
\hline Palo Verde & & & & & & \\
\hline
\end{tabular}

(Si nunca ha visitado ninguna biblioteca pase a la pregunta 23)

16- ¿Cómo se dio cuenta de la existencia de estas bibliotecas? (Marque solo una opción).
a- __ Por medio de un profesor(a)
b- __ Por medio de un compañero(a) de la universidad
c- __ Por medio de un compañero(a) de trabajo
d- _ Por medio de Internet
e- __ Otro, especifique

17- ¿Para cuáles de las siguientes actividades requería la información que buscaba?

(Puede marcar más de una opción).
a- $\quad$ Para realizar sus trabajos académicos
b- _ Para realizar sus trabajos personales de investigación
c- _ Para actualización de sus conocimientos
d- $\quad$ Otro, especifique

18- En su visita a la biblioteca, ¿encontró la información que necesitaba?
a- Sí
b- No

19- ¿El material brindado le fue útil?

aSí bNo

Comente si lo considera necesario:

20- De los siguientes aspectos, ¿cuál es su grado de satisfacción, en relación con cada biblioteca? (CRO: Biblioteca Central, LS: La Selva, LC: Las Cruces, PV: Palo Verde) 


\begin{tabular}{|c|c|c|c|c|c|c|c|c|c|c|c|c|c|c|c|c|}
\hline \multirow{2}{*}{ Aspecto } & \multicolumn{4}{|c|}{$\begin{array}{c}\text { Muy } \\
\text { satisfecho }\end{array}$} & \multicolumn{4}{|c|}{ Satisfecho } & \multicolumn{4}{|c|}{$\begin{array}{c}\text { Poco } \\
\text { satisfecho }\end{array}$} & \multicolumn{4}{|c|}{ Insatisfecho } \\
\hline & $\begin{array}{l}\text { CR } \\
\mathrm{O}\end{array}$ & $\mathrm{L}$ & $\mathrm{L}$ & $\begin{array}{l}\mathrm{P} \\
\mathrm{V}\end{array}$ & $\begin{array}{l}\text { CR } \\
\mathrm{O}\end{array}$ & $\begin{array}{l}L \\
S\end{array}$ & $\begin{array}{l}\mathrm{L} \\
\mathrm{C}\end{array}$ & $\begin{array}{l}\mathrm{P} \\
\mathrm{V}\end{array}$ & $\begin{array}{l}\text { CR } \\
\mathrm{O}\end{array}$ & L & LC & $\begin{array}{l}\mathrm{P} \\
\mathrm{V}\end{array}$ & $\begin{array}{l}\text { CR } \\
\mathrm{O}\end{array}$ & $\begin{array}{l}\mathrm{L} \\
\mathrm{S}\end{array}$ & $\begin{array}{l}\mathrm{L} \\
\mathrm{C}\end{array}$ & $\begin{array}{l}\mathrm{P} \\
\mathrm{V}\end{array}$ \\
\hline $\begin{array}{l}\text { Atención } \\
\text { brindada }\end{array}$ & & & & & & & & & & & & & & & & \\
\hline Horario & & & & & & & & & & & & & & & & \\
\hline $\begin{array}{l}\text { Ubicación } \\
\text { geográfica de } \\
\text { la biblioteca }\end{array}$ & & & & & & & & & & & & & & & & \\
\hline $\begin{array}{l}\text { Instalaciones } \\
\text { físicas de la } \\
\text { biblioteca }\end{array}$ & & & & & & & & & & & & & & & & \\
\hline $\begin{array}{l}\text { Información } \\
\text { suministrada }\end{array}$ & & & & & & & & & & & & & & & & \\
\hline $\begin{array}{l}\text { Servicios y } \\
\text { productos de } \\
\text { información }\end{array}$ & & & & & & & & & & & & & & & & \\
\hline $\begin{array}{l}\text { Ambiente de } \\
\text { la biblioteca }\end{array}$ & & & & & & & & & & & & & & & & \\
\hline Silencio & & & & & & & & & & & & & & & & \\
\hline $\begin{array}{l}\text { Bases de } \\
\text { datos }\end{array}$ & & & & & & & & & & & & & & & & \\
\hline Iluminación & & & & & & & & & & & & & & & & \\
\hline Ventilación & & & & & & & & & & & & & & & & \\
\hline $\begin{array}{l}\text { Colecciones } \\
\text { digitales }\end{array}$ & & & & & & & & & & & & & & & & \\
\hline $\begin{array}{l}\text { Colecciones } \\
\text { bibliográficas }\end{array}$ & & & & & & & & & & & & & & & & \\
\hline
\end{tabular}

21- ¿Considera valiosas las bibliotecas de la OET?

a- _ Sí b-__ No ¿Por qué?

22- Tiene alguna sugerencia para mejorar algún aspecto en el Sistema de Bibliotecas de la OET.

23- Si no ha visitado las bibliotecas de la OET, ¿indique por qué razón nunca las ha visitado?

(Puede marcar más de una opción).
a- ___ Considero que estas bibliotecas son solo para investigadores y estudiantes.

b-___ No me gusta leer. 
c- ___ No tengo tiempo.

d-__ Me encuentro en otro país.

e- ___ No me es de interés la temática de la biblioteca.

f- __ Otra, especifique

24- ¿Considera que el Sistema de Bibliotecas contribuye al cumplimiento de la misión y los objetivos de la OET?
a-
Sí
b-
No
C-
$\mathrm{NS} / \mathrm{NR}$

¿Por qué?

25- De acuerdo con sus necesidades, ¿cuál sería el horario más adecuado para visitar la biblioteca?

(Puede marcar más de una opción).
a-
En la mañana
d- Jornada continua
b- En la tarde
e- Sábados
c- En la noche
f- Domingos

26- ¿En qué tipo de formato prefiere la información?
a-
Digital
b-
Impreso
C- Ambos

\section{Parte. Servicios y productos de información}

27- De los servicios y productos que ofrece el Sistema de Bibliotecas de la OET, ¿cuáles conoce? ¿cuáles utiliza?

\begin{tabular}{|l|c|c|c|c|}
\hline \multicolumn{1}{|c|}{ Servicio o producto } & \multicolumn{2}{c|}{ Conoce } & \multicolumn{2}{c|}{ Utiliza } \\
\cline { 2 - 5 } & Sí & No & Sí & No \\
\hline BINABITROP Costa Rica & & & & \\
\hline BINABITROP América Central & & & & \\
\hline Catálogo en línea de la biblioteca & & & & \\
\hline $\begin{array}{l}\text { Base de datos de las investigaciones de los } \\
\text { cursos de la OET }\end{array}$ & & & & \\
\hline Préstamo de material a sala & & & & \\
\hline Préstamo de material a domicilio por correo & & & & \\
\hline $\begin{array}{l}\text { Solicitudes de información } \\
\text { electrónico o teléfono }\end{array}$ & & & \\
\hline Bibliografías especializadas & & & & \\
\hline Boletín semanal: "La Referencia de Hoy" & & & & \\
\hline Servicio de fotocopiado & & & & \\
\hline Escaneo de documentos & & & & \\
\hline Búsquedas de información especializadas & & & & \\
\hline Atención de solicitudes recibidas por medio del & & & \\
\hline
\end{tabular}


Sistema de Información y Documentación Agropecuario de las Américas (SIDALC) Preparación de libros que los cursos de la OET llevan al campo

28- De acuerdo con sus intereses, ¿qué otros servicios o productos le gustaría que estas bibliotecas le ofrecieran?

29- Con respecto a las colecciones de las bibliotecas de la OET, ¿qué opinión le merecen?
a- _ Muy actuales
b- Actuales
c- Poco actuales
d- Desactualizadas
e- _ NS/NR

30- ¿Ha participado como estudiante de algún curso impartido por la OET?
a-
Sí
b- No

(Si su respuesta es negativa, fin del cuestionario, muchas gracias por su colaboración).

31- Durante el curso, ¿se le brindó información sobre las bibliotecas de la OET?
a-
Sí
b- No

32- Con respecto a los libros que el curso llevó, ¿los consultó? ¿le fueron útiles?
a- Los consultó
b- Le fueron útiles
Sí ( ) No ( )
c- No sabía que se llevaron libros
Sí ( ) No ( )

(Si los libros le fueron útiles, fin del cuestionario, muchas gracias por su colaboración)

33- ¿Por qué no le fueron útiles estos libros?

(Puede marcar más de una opción).
a- __ Estaban muy desactualizados.
b- __ No habían libros sobre mi tema de investigación.
c- _ Toda la información la encontré en Internet.
d- Toda la información la encontré en las bases de datos de mi universidad.
e- _ Otra, especifique

¡Muchas gracias por su colaboración! 


\section{e-Ciencias de la Información}

¿Desea publicar su trabajo?

Ingrese aquí

O escríbanos a la siguiente dirección: revista.ebci@ucr.ac.cr

(우(1)(2)

\section{1}

Origen: respuesta a una necesidad

En el año 2011, la Escuela de

Bibliotecología y Ciencias de la Información (EBCl) de la Universidad de Costa Rica (UCR) reconoció la importancia de crear nuevas y mejores alternativas para difusión de la investigación. e-Ciencias de la Información es la respuesta a un contexto actual marcado por una mayor apertura, flexibilidad, y rigurosidad en la verificación de los datos y su procesamiento.

\section{3}

Revista de la UCR

e-Ciencias de la Información es una revista científica que aborda las nuevas temáticas de desarrollo e investigación en las Ciencias de la Información, en el ámbito nacional e internacional. Así, colabora significativamente en el progreso de esta disciplina. Por sus parámetros de calidad, pertenece al grupo de las revistas más importantes de la UCR y se encuentra ampliamente indizada en los importantes catálogos.

\section{En la actualidad}

Posicionamiento internacional

La revista admite trabajos en las siguientes áreas, siempre que se relacionen directamente con las Ciencias de la Información:

Bibliotecología, Documentación, Tecnologías de la Información y la Comunicación, Investigación, Análisis Estadísticos y Bibliometría, Archivística, Sistemas de Información, Informática, Comunicación y Biblioteas Escolares.

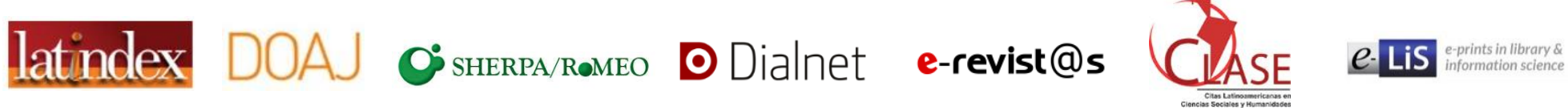

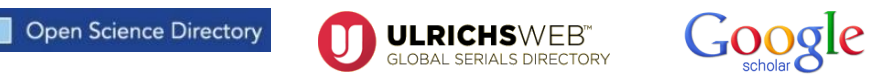

